\title{
Improved High-Temperature Aluminum Alloys Containing Cerium
}

\author{
David Weiss
}

(Submitted August 7, 2018; in revised form January 3, 2019; published online February 1, 2019)

\begin{abstract}
A common rare earth (cerium) when added to aluminum in compositions up to the eutectic compositions of around $10 \mathrm{wt} . \%$ improves the high-temperature performance of aluminum alloys. In the early 1980s, some promising research and development efforts focused on powder metallurgy revealed that aluminum alloys containing $4 \mathrm{wt} \%$ cerium exhibit high-temperature mechanical properties exceeding those of the best commercial aluminum casting alloys then in production. Those compositions, which also included high levels of iron, were difficult to process. Recently, magnesium replaces iron to reduce density and improve processing. Cerium oxide is an abundant rare earth oxide that is often discarded during the refining of more valuable rare earths such as $\mathrm{Nd}$ and Dy. Therefore, the economics are compelling for cerium as an alloy additive. In this review, we report results obtained during an investigation of the processing and properties of aluminum-cerium alloys produced via casting, extrusion and additive manufacturing. The results show mechanical properties are retained at higher temperatures than other aluminum alloys and show complete recovery of mechanical properties at room temperature when exposed to elevated temperatures as high as $500{ }^{\circ} \mathrm{C}$ for $1000 \mathrm{~h}$. Alloys containing cerium also have superior corrosion properties when compared to most aluminum alloys.
\end{abstract}

Keywords Al-Ce alloy, aluminum, cerium intermetallics, nonferrous metals, rare earths

\section{Background and History}

Initial analysis of the Al-Ce system using substantial amounts of Ce via powder metallurgy followed by hot forging showed promising strengths of an $\mathrm{Al}-8 \mathrm{Fe}-4 \mathrm{Ce}$ alloy at temperatures up to $343{ }^{\circ} \mathrm{C}(\operatorname{Ref} 1)$. The casting characteristics of these alloys were unknown.

Other authors have considered using cerium as an alloy addition for aluminum casting alloys. In a series of papers (Ref $2,3)$, Shikun reviewed the effect of additions of cerium of up to 6 wt. $\%$ on the solidification range, solidification volume change, hot tearing tendency and cast microstructure in an Al-4.5 $\mathrm{Cu}$ alloy. He concluded that the addition of cerium up to 4 wt.\% generally improved the casting characteristics of the alloy, but he did not study the mechanical properties of the various compositions. Belov (Ref 4) considered $\mathrm{Ce}$ in the development of creep-resistant aluminum alloys along with high- and low-solubility transition metals. He concluded that to

This article is an invited submission to JMEP selected from presentations at the 29th Advanced Aerospace Materials and Processes (AeroMat) Conference and Exposition held May 7-10, 2018 , in Orlando, Florida, and has been expanded from the original presentation.

David Weiss, Eck Industries, Manitowoc, WI. Contact e-mail: david.weiss@eckindustries.com. obtain the optimum combination of creep strength and casting properties aluminum solid solution alloyed with soluble transition metals ( $\mathrm{Zr}, \mathrm{Mn}$ and $\mathrm{Cr}$ ) and a second phase containing transition metals with low solubility (Fe, Ni, Ce) should be used. Later (Ref 5), Belov focused on the Al-Ce-Ni system, studying the microstructure and mechanical properties of Al-Ce-Ni alloys containing up to $16 \mathrm{wt} \% \mathrm{Ce}$ and $8 \mathrm{wt} . \% \mathrm{Ni}$. $\mathrm{He}$ concluded that alloys of the Al-Ce-Ni ternary eutectic system (12 wt.\% Ce, 6 wt.\% Ni) demonstrate high mechanical properties at room and elevated temperatures along with very good casting properties.

Aluminum alloys with $\mathrm{Si}$ as the major alloying element are the most important Al-based foundry alloys because of their excellent casting characteristics. Gröbner et al. (Ref 6) studied aluminum alloys containing up to 25 at.\% Ce and 45 at. $\%$ Si. He concluded that Ce between 1 and 5 at.\% could be used as a nucleant grain refiner and that the lowering of the liquidus and growth temperature of $\mathrm{Si}$ by $\mathrm{Ce}$ additions appeared promising.

The further development of Al-Ce casting alloys is driven by two goals. First is the increasing demand for hightemperature tolerant aluminum alloys. Second is finding a use for the excess cerium oxide that was available as a by-product of the production of the heavy rare earths such as Nd, Dy and $\mathrm{Sm}$.

\section{Metallurgical Aspects of the Al-Ce System}

The equilibrium diagram, Ce-Al crystal structure data and Ce-Al lattice parameter date were reviewed in 1988 (Ref 7), and a eutectic composition of $\mathrm{Al}$ and $\mathrm{Al}_{11} \mathrm{Ce}_{3}$ was shown at 4 at. $\% \mathrm{Ce}$ at $660{ }^{\circ} \mathrm{C}$. Recently calculated Thermo-Calc data predicted a eutectic of $\mathrm{Al}_{11} \mathrm{Ce}_{3}$ at $580{ }^{\circ} \mathrm{C}$ at 10 wt.\% [2.09 at.\%] (Ref 8). 

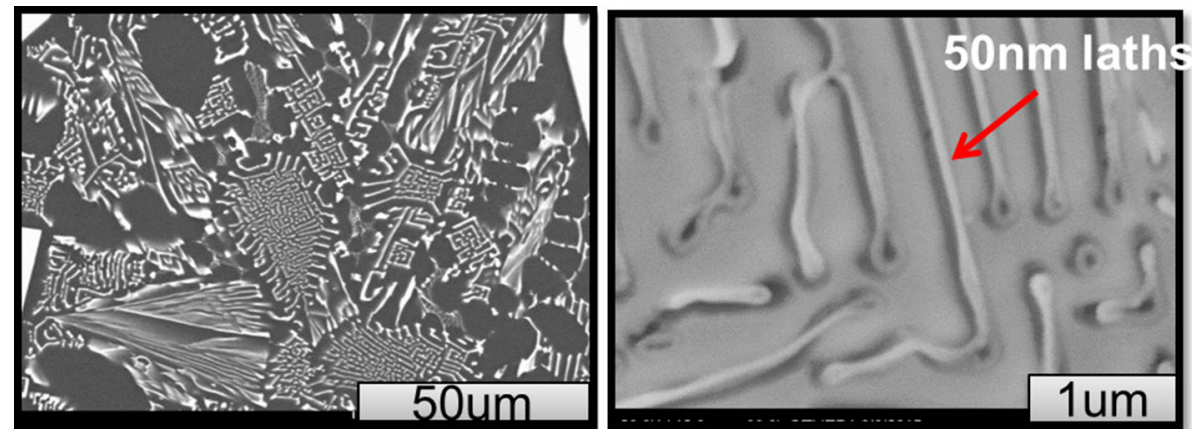

Fig. 1 Typical microstructure of binary Al-Ce alloy showing $\mathrm{Al}_{11} \mathrm{Ce}_{3}$ intermetallic

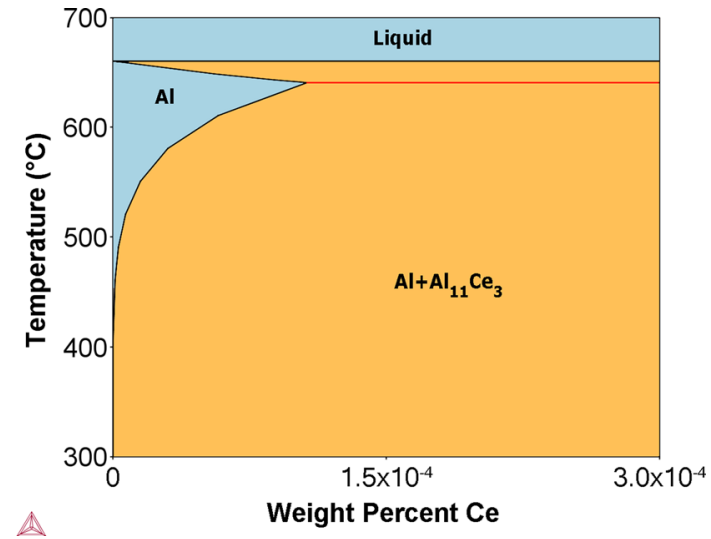

Fig. 2 The Al-rich area of the Al-Ce phase diagram showing limited Ce solubility from Ref 4

Microstructures typical of this alloy system are shown in Fig. 1. The as-cast microstructures show a very fine interconnected eutectic microstructure and the pure aluminum phase. The scale of the laths can be as small as $100 \mathrm{~nm}$ and do not exhibit preferential direction at standard cooling rates. These structures are stable at higher temperatures. The intermetallics are trapped by the zero solubility of cerium in the aluminum matrix. This trapping prevents the system from minimizing surface energy through diffusion, which blocks the alloys from traditional coarsening interactions. A solubility diagram for the binary Al-Ce system is shown in Fig. 2. High temperature yield strength retention is about three times conventional alloys when tested at $300{ }^{\circ} \mathrm{C}$. For Al-Ce alloy systems that use solid solution strengthening elements such as magnesium and/or zinc to improve room temperature strength, room temperature properties do not deteriorate regardless of length of exposure to temperatures of $400{ }^{\circ} \mathrm{C}$. The data in Fig. 3 show a slight increase in properties, due to homogenization of magnesium in the structure. In these solid solution-strengthened alloys, there are no phases that dissolve or coarsen at that temperature such $\mathrm{Mg}_{2} \mathrm{Si}$ or $\mathrm{Al}_{2} \mathrm{Cu}$.

Load partitioning studies in compression conducted by Oak Ridge National Laboratory at their Vulcan Beam Line show unusual load sharing behavior between the matrix and the $\mathrm{Al}_{11} \mathrm{Ce}_{3}$ intermetallic. As illustrated in Fig. 4, as the compressive stress increases, a higher proportion of that stress is transferred to the intermetallic. An extensive analysis of the strengthening mechanisms and microstructural analysis of the Al-Ce system can be found in Ref 8 .

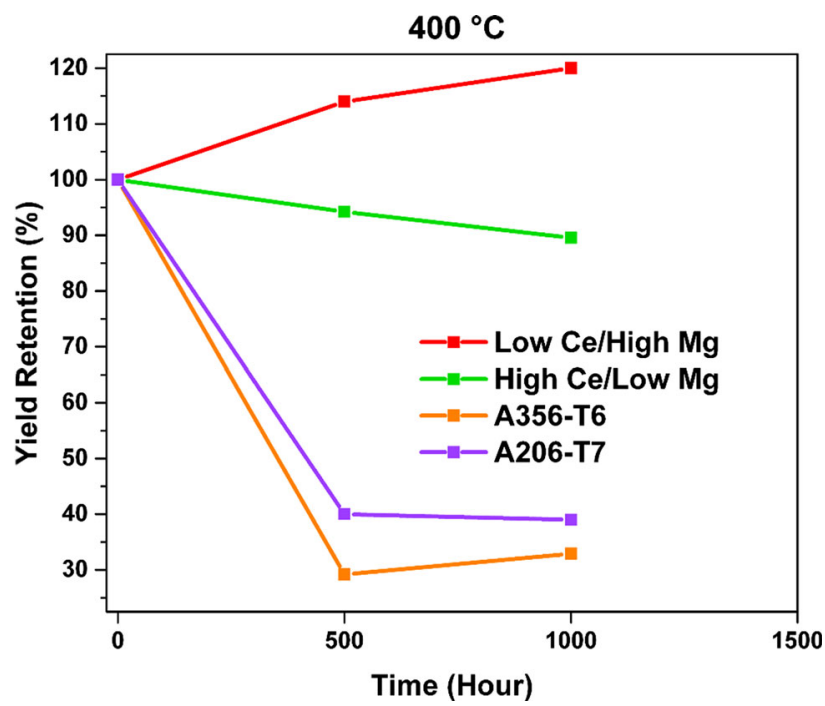

Fig. 3 Long-term exposure data of Al-Ce alloys measured at room temperature compared to some standard casting alloy

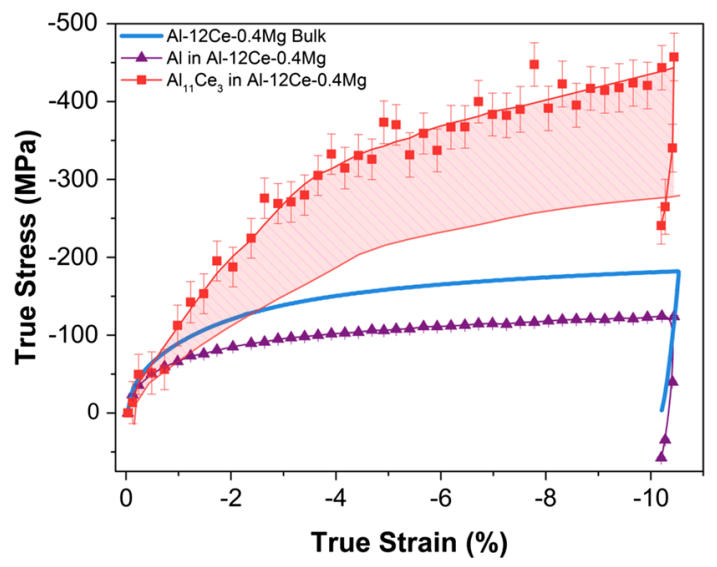

Fig. 4 Phase load sharing for $\mathrm{Al}-12 \mathrm{Ce}-0.4 \mathrm{Mg}$ under compressive load. Shaded region denotes difference between binary and ternary alloy composition's mechanical response from Ref 4

\section{Alloying Element Interactions}

At room temperature, the $\mathrm{Al}_{11} \mathrm{Ce}_{3}$ intermetallic is not an effective strengthening mechanism. Mechanical properties for pure binary compositions are shown in Table 1. To develop reasonable room temperature strengths, other alloying elements 
such as $\mathrm{Mg}, \mathrm{Zn}, \mathrm{Cu}$, Si or others can be added along with Ce to strengthen the aluminum matrix. Sun et al. (Ref 9) looked at Ce-alloy systems using first-principles calculations to understand the compound-forming characteristics of this element. Several promising compounds were identified, including $\mathrm{Ce}$ $\mathrm{Fe}, \mathrm{Ce}-\mathrm{Co}, \mathrm{Ce}-\mathrm{Ni}, \mathrm{Ce}-\mathrm{Cu}$ and $\mathrm{Ce}-\mathrm{Zn}$. Compound-forming ability may or may not increase strength, since it may immobilize elements required for strengthening during heat treatment.

Magnesium is an effective strengthening element for the aluminum matrix. The strengthening is based on the size and modulus misfit of the magnesium in the aluminum which increases the initial yield stress and reduces the dynamic recovery rate of dislocations (Ref 10 ). The addition of 10 percent magnesium in an Al-8Ce alloy increases the yield strength by over $300 \%$ from about $50 \mathrm{Mpa}$ to about $162 \mathrm{Mpa}$. The primary intermetallic does not contain magnesium, and the improved performance is primarily the result of matrix strengthening.

When copper is added as an alloying element, it interacts directly with the $\mathrm{Ce}$, creating immobile $\mathrm{Cu}-\mathrm{Ce}$ phases. This is illustrated in Fig. 5 using a $4.5 \% \mathrm{Cu}$ alloy with addition of 0.1 and $8 \% \mathrm{Ce}$. There are important implications for this. Most of the $\mathrm{Cu}$ is not free to strengthen the alloy since it is tied up with the Ce phase. The alloy shows limited response to heat treatment. The Ce changes the intergranular corrosion behavior of aluminum alloys. Intergranular corrosion is caused by potential differences between the grain boundary region and the adjacent grain bodies. In copper-containing alloys, the anodic path is the copper-depleted zone on either side of the grain boundary and in alloys containing magnesium it is the anodic constituent $\mathrm{Mg}_{2} \mathrm{Al}_{3}$ when that constituent forms a continuous path around the grain boundary (Ref 11$)$. In the case of coppercontaining alloys (Fig. 6), the cerium acts as a diffusion barrier, preventing the formation of copper-depleted zones. The exact mechanism of corrosion reduction in Al-Mg alloys is still under investigation. In all alloys tested, the addition of small amounts of cerium increases their resistance to intergranular corrosion, as shown in Fig. 7.

\section{Product Forms}

Recent development of the Al-Ce system has concentrated on casting development. The casting characteristics of the binary Al-Ce systems is as good as the aluminum-silicon system with some deterioration as additional alloying elements are added (Ref 12). In alloy systems that use cerium in combination with common aluminum alloying elements such as silicon, magnesium and/or copper, the casting characteristics are generally better than the aluminum-copper system. In

Table 1 Mechanical properties of Al-Ce binary alloys

\begin{tabular}{|c|c|c|c|}
\hline & Tensile Mpa, as cast & Yield Mpa, as cast & $\% E$, as cast \\
\hline $\mathrm{Al}-16 \mathrm{Ce}$ & 144 & 68 & 2.5 \\
\hline $\mathrm{Al}-12 \mathrm{Ce}$ & 163 & 58 & 13.5 \\
\hline $\mathrm{Al}-10 \mathrm{Ce}$ & 152 & 50 & 8 \\
\hline Al-8 Ce & 148 & 40 & 19 \\
\hline $\mathrm{Al}-6 \mathrm{Ce}$ & 103 & 30 & 25 \\
\hline
\end{tabular}

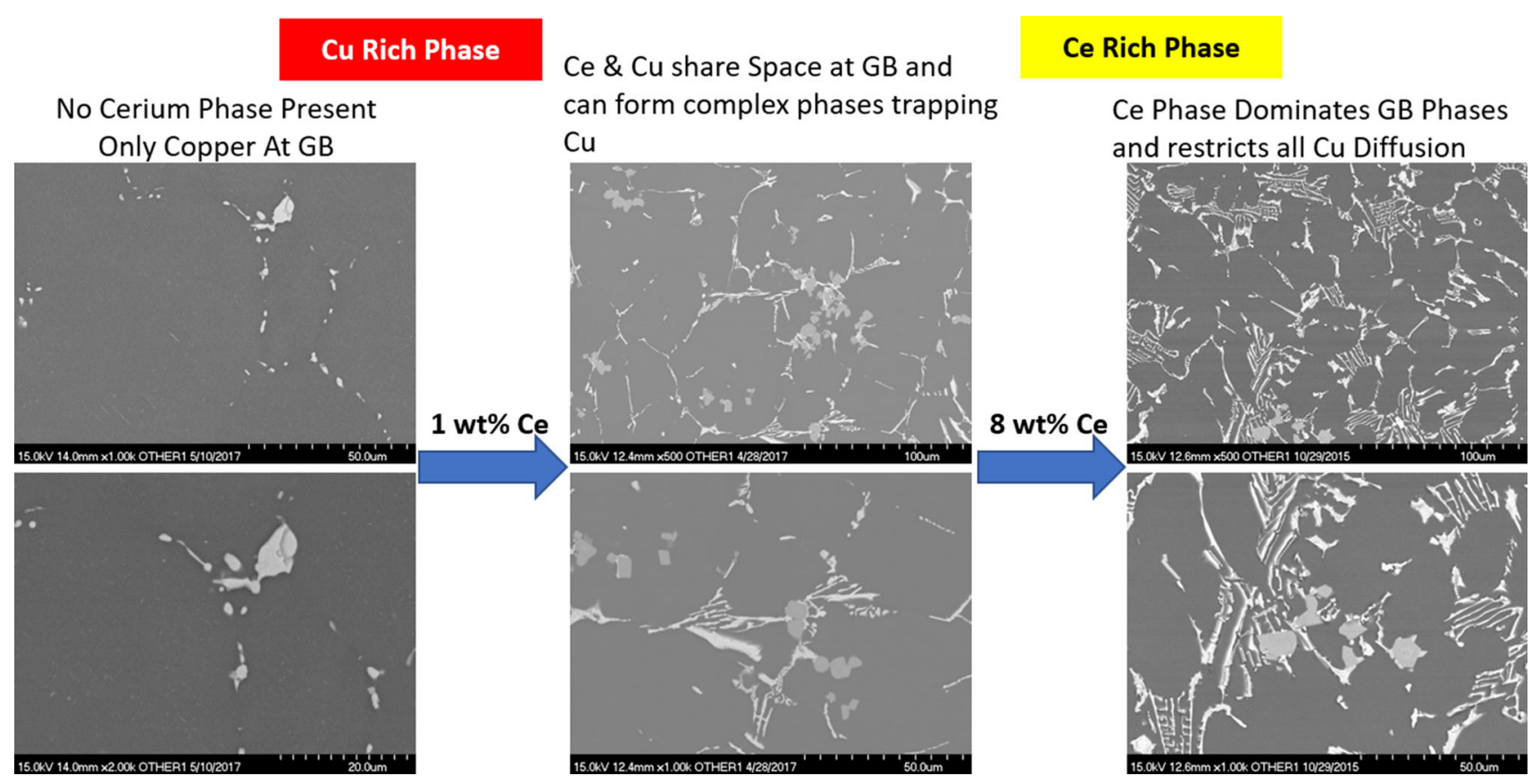

Fig. 5 Increasing cerium addition precipitates immobile $\mathrm{Al}-\mathrm{Ce}$ and $\mathrm{Ce}-\mathrm{Cu}$ phase at grain boundary 
Alloy A206

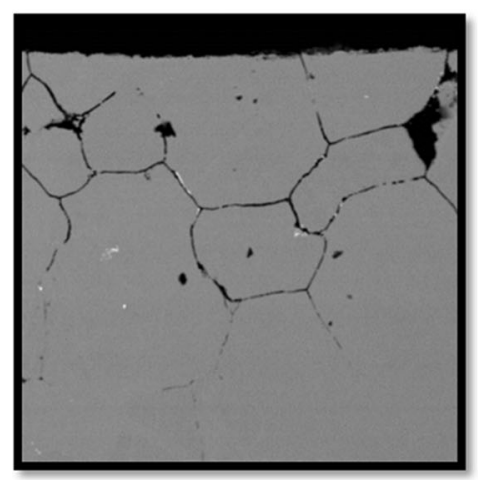

$1 \%$ Ce addition

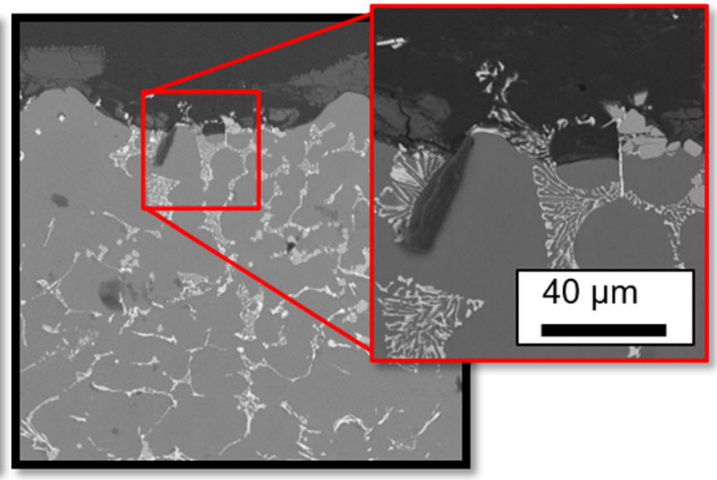

Fig. 6 The addition of $\mathrm{Ce}$ to $\mathrm{Al}-\mathrm{Cu}$ alloys acts as a diffusion barrier by blocking grain boundary motion

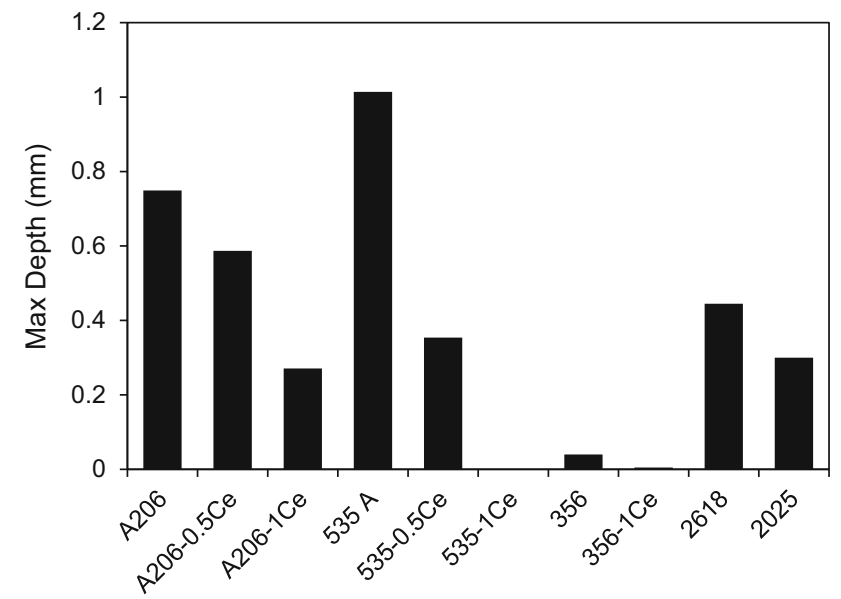

Fig. 7 ASTM G110-92(15) intergranular attack test; submerged in hydrogen peroxide with $\mathrm{NaCl}$

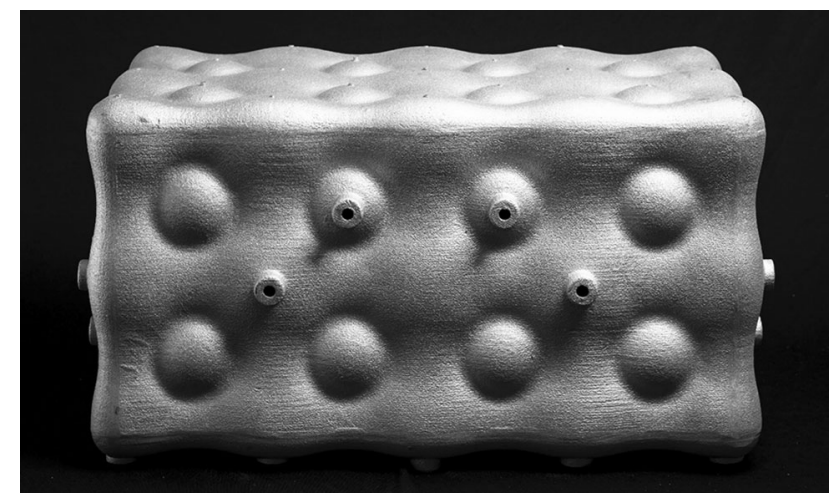

Fig. 8 Cast 21X12X17.5" conformal storage tank cast from Al-Ce$\mathrm{Mg}$ alloy

general, production systems for melting, de-gassing and other processing of aluminum-silicon or aluminum-copper alloys can be used without modification for conventional casting of aluminum-cerium alloys.

Previous work by the author shows some benefits to the structure using a single-stage homogenization heat treatment to disperse pools of magnesium that form under slow solidification conditions (Ref 13). The alloys have been cast successfully

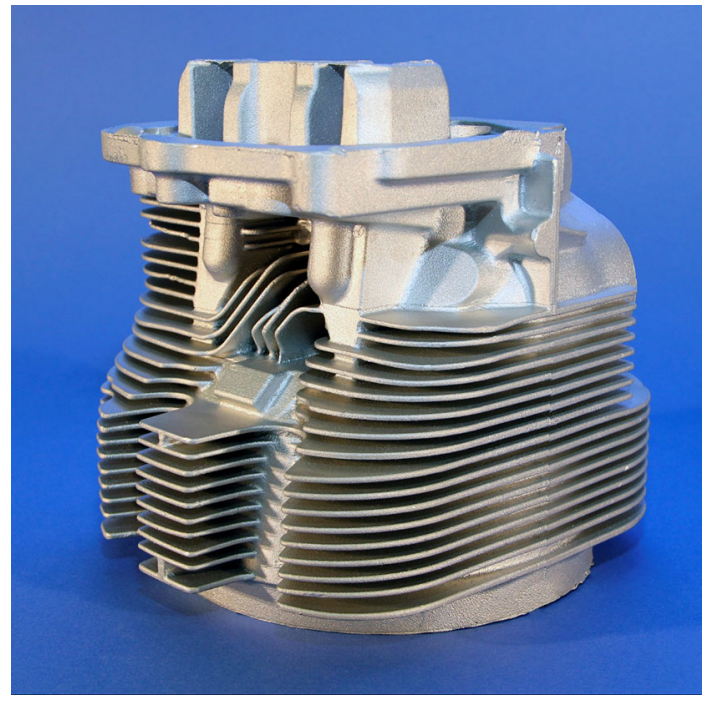

Fig. 9 General aviation cylinder head produced from Al-Ce binary alloy

in sand, permanent mold, low pressure permanent and die casting processes. Figure 8 shows a conformal storage tank produced from an aluminum-cerium-magnesium alloy as a lowpressure precision sand casting. A gravity cast aircraft cylinder head is shown in Fig. 9.

Mechanical properties for the ternary Al-Ce-Mg system have been extensively studied. These alloys have acceptable room temperature properties and very good high-temperature properties (Table 2). The room temperature properties can be improved somewhat by homogenization or hot isostatic pressing. One of the key differences in the Al-Ce-Mg system and other high-temperature aluminum alloys is the recovery of mechanical properties at room temperature when exposed to elevated temperatures for prolonged periods of time. This occurs through homogenization of the magnesium structure and the lack of precipitates that become unstable after prolonged high-temperature exposure.

Preliminary extrusion work has been done in the Al-Mg-Ce system. Extrusion improves the properties through a combination of work hardening and alignment of the intermetallic. Extrusions were produced at $300{ }^{\circ} \mathrm{C}$ billet temperature at an extrusion ratio of 5.75 to 1 and 52 to 1 from an $\mathrm{Al10Mg} 8 \mathrm{Ce}$ alloy. A comparison of average permanent mold as-cast 
Table 2 Room and elevated temperature properties of Al-10Mg-8Ce compared to common piston alloys

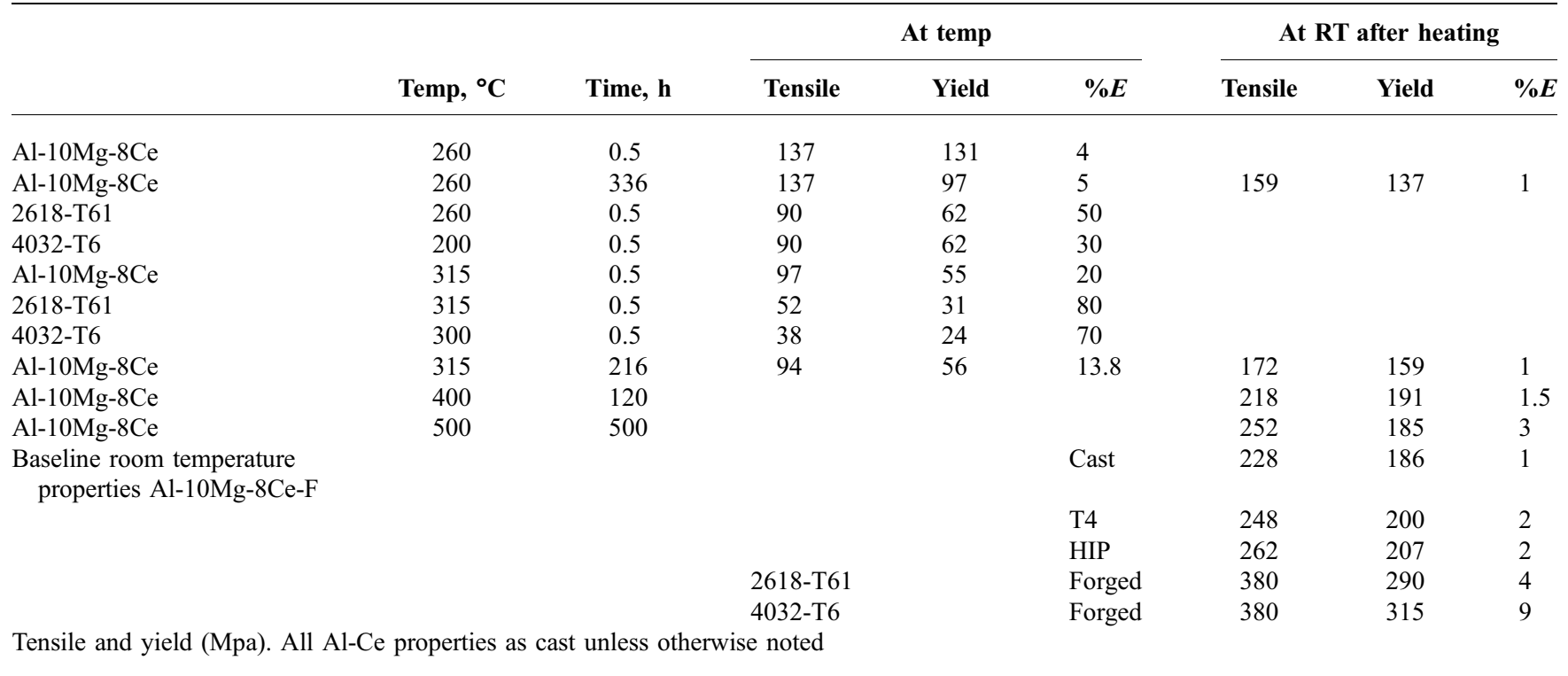

Table 3 Comparison of extruded data at different extrusion ratios with cast Al10Mg8Ce

\begin{tabular}{lccc}
\hline & \multicolumn{3}{c}{ Al10Mg8Ce-F } \\
\cline { 2 - 4 } & Tensile & Yield & \% $\boldsymbol{E}$ \\
\hline Extrusion 5:1 & 375 & 342 & 5.8 \\
Extrusion 52:1 & 364 & 274 & 12 \\
Permanent mold & 228 & 186 & 1 \\
\hline
\end{tabular}

properties to extruded properties is shown in Table 3. As the extrusion ratio increases, tensile strength remains constant, with the increase in elongation and decrease in yield strength.

The alloy system has been used for both the direct write and powder bed fusion. Manca et al. (Ref 14) have reported high mechanical properties of $\mathrm{Al}-3 \mathrm{Ce}-7 \mathrm{Cu}$ in both high-temperature tension and compression testing via selective laser melting. Fine eutectic phases of $\mathrm{Al}_{11} \mathrm{Ce}_{3}$ and $\mathrm{Al}_{6.5} \mathrm{CeCu}_{6.5}$ were found in the microstructure. High hardness values were noted after annealing at $400{ }^{\circ} \mathrm{C}$ due to the precipitation of nanosized particles. Kessler et al. (Ref 15) used induction heated Al-Ce wire to take advantage of the inherent rheology of molten Al$\mathrm{Ce}$ and the high enthalpy of fusion for the reactive Cecontaining intermetallic. This intermetallic phase enhances the surface energy and stabilizes the extruded filament, imparting shape stability and facilitating layer to layer joining.

\section{Economic Considerations}

Cerium is the most abundant rare earth. With the current price of metallic cerium in the $\$ 4-5 / \mathrm{lb}$. range, the use of cerium as an alloying element is economically feasible for high-volume production. The as-alloyed cost of Al-Ce material is competitive with other high-performance aluminum alloy systems. Cerium has commercial utility for corrosion protection ( $\sim 1 \% \mathrm{Ce})$ as well as high-temperature strength improvement $(\sim 6-10 \% \mathrm{Ce})$. Further cost reduction in $\mathrm{Ce}$ is enabled by direct metallothermic reduction of cerium oxide. Luna et al. (Ref 16) directly reduced the oxide on a laboratory scale in aluminum alloys containing between 0.5 and $4.0 \mathrm{wt} . \% \mathrm{Mg}$. This technique is now being developed on a commercial scale.

\section{Conclusions}

A new alloy system has been developed that uses the abundant rare earth element $\mathrm{Ce}$ as the primary alloying element. These alloys have good casting and forming characteristics along with better corrosion performance than most aluminum alloys. Performance at high temperatures with long exposure times is better than most aluminum alloys. These attributes combined with affordable prices make the Al-Ce system useful for lightweight high-performance applications in the automotive, trucking, aerospace and other industrial sectors.

\section{References}

1. W.M. Griffith, R.E. Sanders, and G.J. Hildeman, Elevated Temperature Aluminum Alloys for Aerospace Applications, in High-Strength Powder Metallurgy Aluminum Alloys, Proceedings of a symposium sponsored by the Powder Metallurgy Committee of the Metallurgical Society of AIME, 17-18 Feb, 1982

2. X. Shikun, Y. Rongxi, G. Zhi, X. Xiang, H. Chagen, and G. Xiuyan, Effects of Rare Earth Ce on Casting Properties of Al-4.5Cu Alloy, $A d v$. Mater. Res., 2010, 136, p 1-4

3. X. Shikun, A. Yongping, G. Zhi, X. Xiang, Y. Rongxi, G. Zhi, and G. Xiuyan, Effects of Ce Addition on the Mobility and Hot Tearing Tendency of Al-4.5Cu Alloy, Adv. Mater. Res., 2010, 146-147, p 481484

4. N.A. Belov, Principles of Optimising the Structure of Creep-Resisting Casting Aluminum Alloys Using Transition Metals, J. Adv. Mater., 1994, 1(4), p 321-329

5. Nikolay A. Belov, Evgeniya A. Naumova, and Dmitry G. Eskin, Casting Alloys of the Al-Ce-Ni System: Microstructural Approach to Alloy Design, Mater. Sci. Eng. A, 1999, 271(1), p 134-142

6. J. Gröbner, D. Mirkovic, and R. Schmid-Fetzer, Thermodynamic Aspects of the Constitution, Grain Refining, and Solidification 
Enthalpies of Al-Ce-Si Alloys, Metall. Mater. Trans. A, 2004, 35, p 3349

7. K. Gschneidner and F.W. Calderwood, The Al-Ce (Aluminum-Cerium) System, Bull. Alloy Phase Diagr., 1988, 9(6), p 669

8. Z. Sims et al., High Performance Aluminum-Cerium Alloys for HighTemperature Applications, Mater. Horiz., 2017, 4, p 1070

9. X. Sun, Y. Lei, R. Zhou, and B. Zhang, Novel Compounds of Cerium Binary Alloys from High-Throughput First-Principles Calculations, $J$. Appl. Phys., 2018, 123, p 235102

10. O. Ryen et al., Strengthening Mechanisms in Solid Solution Aluminum Alloys, Metall. Mater. Trans. A, 2006, 37, p 1999

11. ASM International, Metals Handbook, 9th ed., ASM International, Materials Park, 1987, p 589

12. D. Weiss, Development and Casting of High Cerium Content Aluminum Alloys. Transactions of the American Foundry Society 17-013, American Foundry Society, 2017
13. D. Weiss, Thermal Treatment of Al-Mg-Ce Alloys. Transaction of the American Foundry Society 18-101, American Foundry Society, 2018

14. D.R. Manca, et al., Microstructure and Properties of Novel Heat Resistant Al-Ce-Cu Alloy for Additive Manufacturing, Met. Mater Int. 2018. https://doi.org/10.1007/s12540-018-00211-0

15. M. Kesler et al., Liquid Direct Reactive Printing of Structural Aluminum Alloys, Appl. Mater Today, 2018, 13, p 339-343

16. J.S. Luna et al., Cerium Extraction by Metallothermic Reduction Using Cerium Oxide Powder Injection, J. Rare Earths, 2011, 29(1), p 74

Publisher's Note Springer Nature remains neutral with regard to jurisdictional claims in published maps and institutional affiliations. 